\title{
Anterior laparoscopic rectal resection for cancer in the elderly: long-term outcome, risk factors and health related quality of life Massimo Vecchiato*1, Silvia Savastano1, Giacomo Sarzo ${ }^{1}$, Roberto Cadrobbi ${ }^{1}$, Mario Gruppo ${ }^{1}$, Isabella Mondi ${ }^{1}$, Francesco Cavallin², Giuseppina Bazzolo일 Elisa Marcellan ${ }^{1}$ and Stefano Merigliano ${ }^{1}$
}

\author{
Address: ${ }^{1}$ University of Padua, Department of Surgical and Gastroenterologic Sciences, 3th General Surgery Clinic, Coloproctological Unit, "S. \\ Antonio" Hospital, Italy and 2Istituto Oncologico Veneto (IOV-IRCCS), Padua, Italy \\ * Corresponding author
}

\author{
from XXI Annual Meeting of The Italian Society of Geriatric Surgery \\ Terni, Italy. 4-6 December 2008 \\ Published: I April 2009 \\ BMC Geriatrics 2009, 9(Suppl I):A43 doi:I0.II86/I47I-23I8-9-SI-A43
}

This abstract is available from: http://www.biomedcentral.com/I47I-23 I8/9/SI/A43

(c) 2009 Vecchiato et al; licensee BioMed Central Ltd.

\section{Background}

Elderly population in Western countries is rapidly increasing. Literature suggests that radical colorectal resection in the elderly can be safely undertaken with good short and long term results; however results of specific rectal laparoscopic resections are not well defined and so quality of life. The aim of this study was to assess long-term outcome; risk factors and health related quality of life (HRQoL) in elective rectal cancer laparoscopic resection in patients older than 65 years.

\section{Materials and methods}

Between March 2002 and November 2007, 57 patients underwent elective laparoscopic resection for rectal cancer. Of these 32 (56\%) were 65 years of age or older; the remaining 25 were the control group. Perioperative and follow-up data were collected and stored in a database. We assessed: operative findings, histopathological features, postoperative course, follow-up and overall survival. All patients were assessed using the EORTC QLQ C30 and EORTC QLQC38 questionnaire to establish HRQOL.

\section{Results}

Laparoscopic resection for rectal cancer in the elderly is safe with no perioperative mortality and post-operative morbidity similar to younger patients (7\%vs13\%; p = $0.4)$.
The overall survival was lower in the younger patients $(\mathrm{p}$ $=0.0015$; the 5-year overall survival rates were $69 \%$ vs $96.4 \%$ ); but age older than 65 years was not an independent risk factor for overall survival at the multivariate analysis.

The multivariate analysis showed that neoadjuvant radiotherapy $(p=0.04)$ and metastatic nodes $(p=0.006)$ are independent risk factor for overall survival and vascular invasion ( $\mathrm{p}=0.005)$ for local recurrence. HRQoL was similar in the two groups.

\section{Conclusion}

Laparoscopic rectal resection for old patients is safe, with short-term results comparable to that of younger people. Old age is not an independent risk factor for prognosis. We achieved excellent overall long term survival and a good quality of life. 